\title{
A novel mutation in STK11 gene is associated with Peutz-Jeghers Syndrome in Chinese patients
}

\author{
Zhiqing Wang, Yulan Chen, Baoping Wu, Haoxuan Zheng, Jiman He and Bo Jiang*
}

\begin{abstract}
Background: Peutz-Jeghers syndrome (PJS) is caused by mutations in the tumor suppressor gene, STK11, and is characterized by gastrointestinal hamartomas, melanin spots on the lips, and an increased risk of developing cancer.

Methods: Blood samples were collected from two unrelated Chinese PJS families totaling 20 individuals ( 9 male and 11 females), including 6 PJS patients. The entire coding region of the STK11 gene was amplified by polymerase chain reaction and analyzed by direct sequencing.

Results: A novel mutation, C.904C > T, in exon 7 was identified in both families. A C > T substitution changed codon 302 from CAG (glutamine) to TAG (stop), truncating the STK11 protein, thus leading to the partial loss of the kinase domain and complete loss of the $\alpha$-helix C-terminus. Furthermore, one PJS patient from each family was diagnosed with a visceral cancer, a colon cancer and a liver cancer respectively.

Conclusion: We predict that this novel mutation, p.Q302X, is most likely responsible for development of the PJS phenotype and may even contribute to malignancy.
\end{abstract}

\section{Background}

Peutz-Jeghers Syndrome (PJS; MIM\#175200) is a rare autosomal dominant disorder characterized by gastrointestinal hamartomatous polyps, mucocutaneous pigmentation, and an increased risk for the development of gastrointestinal (GI) and various extra-GI malignancies $[1,2]$. The relative cancer risk has been estimated to be 9-18 times higher in PJS patients than the general population $[3,4]$.

Mutations in the serine-threonine kinase 11 (STK11/ LKB1, MIM\#602216) gene on chromosome 19p13.3 have been considered to be the major cause of PJS $[5,6]$. The gene is divided into nine exons that encode a 433 amino acid protein, which acts as a tumour suppressor. Mutation detection rates of $10-94 \%$ have been achieved at different centers, depending on the screening method, with considerable uncharacterized genetic heterogeneity remaining in this syndrome $[2,7]$. Most mutations are frameshift or nonsense changes, which result in an abnormal truncated protein and the consequent loss of kinase activity [8]. However, the STK11 mutation

\footnotetext{
* Correspondence: drjiang@163.com Guangdong Provincial Key Laboratory of Gastroenterology, Department of Gastroenterology, Nanfang Hospital, Southern Medical University, Guangzhou 510515, China
}

(c) 2011 Wang et al; licensee BioMed Central Ltd. This is an Open Access article distributed under the terms of the Creative Commons Attribution License (http://creativecommons.org/licenses/by/2.0), which permits unrestricted use, distribution, and reproduction in any medium, provided the original work is properly cited.

\section{Methods}

Family study

Family 1, from Guangdong province, China, consisted of three generations affected with PJS, including two female and two male individuals (Figure 1A). The proband (II:6) died from colon adenocarcinoma at 61 years of age. Family 2, from Hongkong, China, included two PJS patients (Figure 1B). The proband (III:2) in that family underwent abdominal surgery three times due to intussusception and obstruction of the small intestine from Peutz-Jeghers polyps when he was 16, 23, and 25 years old. The mucocutaneous pigmentation faded gradually after his third surgery, but was still visible on his lips and buccal mucosa at the time of this study. His mother (II:2) presented no obvious symptoms until the time of liver cancer diagnosis at 45 years of age. The clinical features of the affected individuals are summarized in Table 1. 
A) Family 1.

$$
\text { I }
$$

II

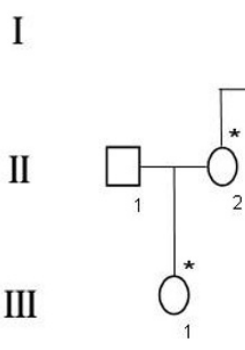

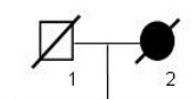

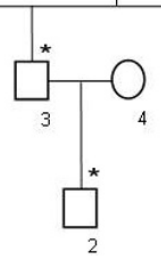

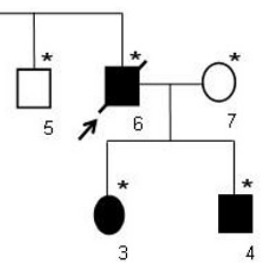

Figure 1 Pedigree of the families with PJS. Roman numerals indicate generations and arabic numbers indicate individuals. Squares $=$ males, circles = females. Affected individuals are denoted by solid symbols and unaffected individuals are denoted by open symbols. A slash denotes that the individual is deceased. The initial proband is indicated by an arrow, and participants in the DNA analysis are marked with an asterisk.

The diagnostic criteria for PJS include the presence of characteristic mucocutaneous pigmentation, the presence of hamartomatous polyps in the gastrointestinal tract, and a family history of PJS. Patients need to fulfill two of these three criteria for a clinical diagnosis of the disease [9]. This study was approved by the Medical Ethics Committee, Nanfang Hospital of Southern Medical University, and informed consent was obtained from all participating individuals.

\section{Mutation detection}

Genomic DNA was extracted from peripheral blood using the QiAamp DNA Blood Midi Kit (Qiagen, Hilden, Germany). PCR primers were designed by Primer 3.0 (http://frodo.wi.mit.edu/primer3/) to amplify the STK11 (GeneBank NM_000455) coding regions and intron-exon boundaries. Details of primer sequences and PCR conditions are available upon request. The PCR products were then sequenced in both directions on an ABI 3730 XL Automated DNA Sequencer (Applied Biosystems, Foster City, CA) with the ABI BigDye Terminator v3.1 cycle sequencing kit. Standard nomenclature (http://www.hgvs.org/mutnomen/) was
B) Family 2.

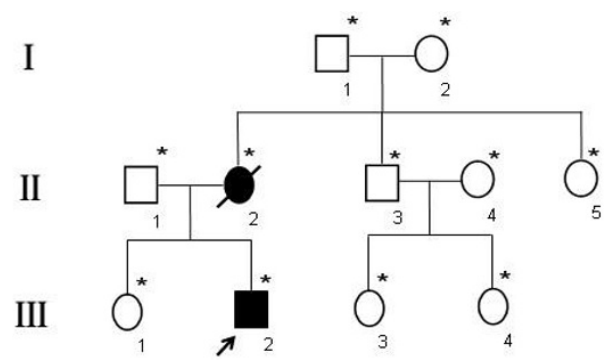

used to describe sequence variations, with +1 corresponding to the A of the ATG translation initiation codon of GeneBank NM_000455 for STK11.

All patients and available family members underwent STK11 germline mutation testing to confirm co-segregation of the mutation with the disease. In order to rule out polymorphisms and to confirm the pathogenic effects of variations, 100 chromosomes from 50 unrelated healthy individuals were also screened for the presence of the mutation.

\section{Structural predictions of the wide-type and mutant STK11} protein

The homology modeling programs, SWISS MODEL (http://swissmodel.expasy.org//SWISS-MODEL.html) and $\mathrm{CPH}$ models, (http://www.cbs.dtu.dk/services/ CPHmodels/) were used to develop an appropriate model to mimic the effects of the mutated region.

\section{Results}

Direct sequencing of the STK11 gene showed a C-to-T transversion of nucleotide 904 in exon 7 in these two unrelated families, which altered the wild-type sequence

Table 1 Characteristics of affected individuals in two Chinese PJS families.

\begin{tabular}{|c|c|c|c|c|c|c|}
\hline \multirow[t]{2}{*}{ Individual } & \multicolumn{2}{|l|}{ Family 1} & \multicolumn{4}{|c|}{ Family 2} \\
\hline & $1: 2$ & II $: 6$ & III : 3 & III : 4 & II : 2 & III : 2 \\
\hline Sex & $\mathrm{F}$ & M & $\mathrm{F}$ & M & $\mathrm{F}$ & M \\
\hline Age at onset of mucocutaneous pigmentations & unknown & 2 years & 3 years & 3 years & 6 months & First year \\
\hline Age at onset abdominal symptoms & 34 & 22 & 14 & 4 & No & 15 \\
\hline $\mathrm{Age}^{*}$ & $34^{*}$ & $61^{*}$ & 27 & 23 & $45^{*}$ & 26 \\
\hline Anemia & unknown & Yes & Yes & Yes & No & Yes \\
\hline Rectal bleeding & unknown & Yes & Yes & Yes & No & Yes \\
\hline Rectal prolapse & unknown & Yes & Yes & No & No & Yes \\
\hline Number of operations for intussusception (Age) & 0 & $122 y$ & $115 y$ & $119 y$ & 0 & $316,23,25 y$ \\
\hline Cause of death & Intussusception & Colon cancer & - & - & Liver cancer & - \\
\hline
\end{tabular}




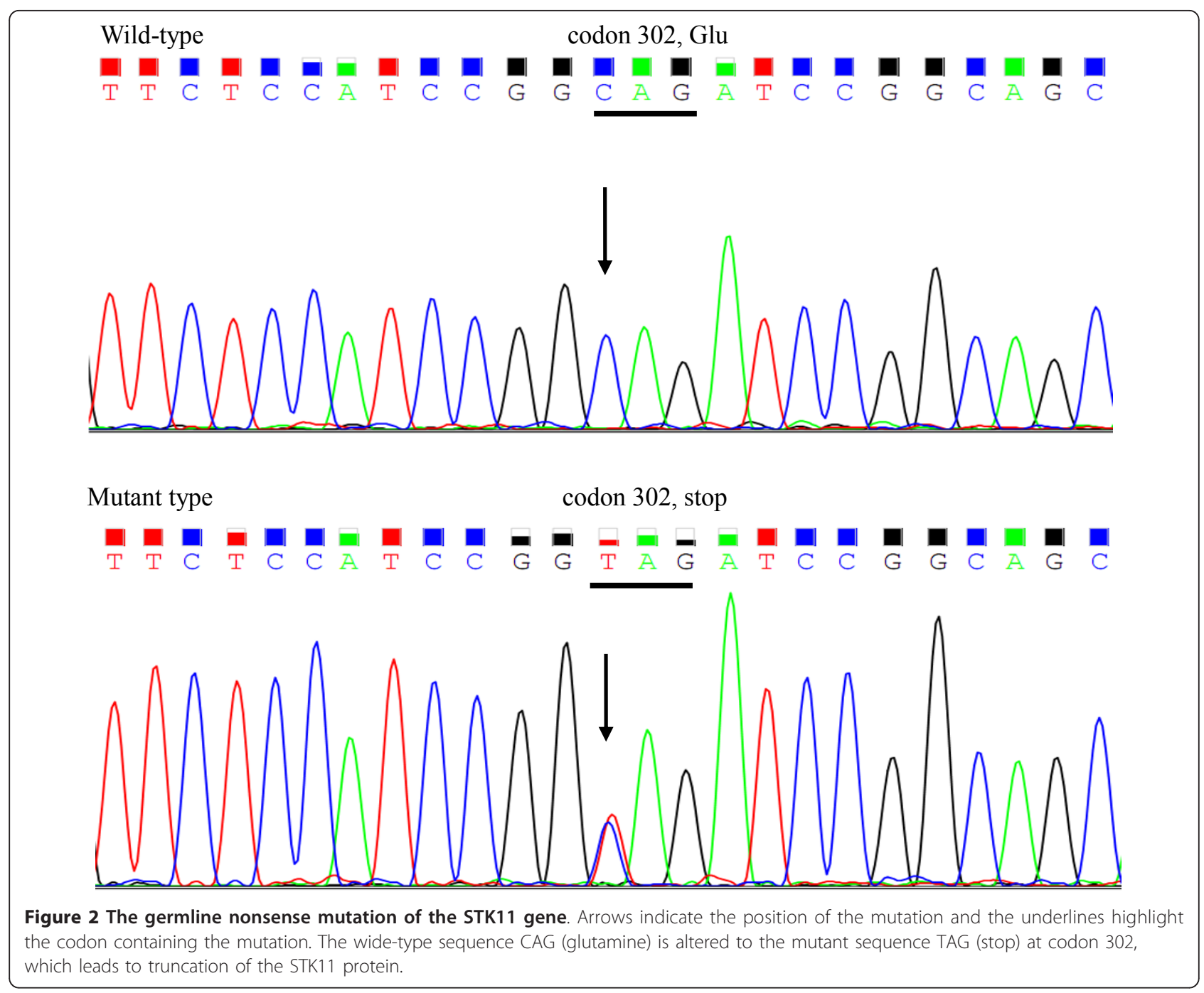

CAG (glutamine) to the mutant sequence TAG (stop) at codon 302, and resulted in a truncation of the STK11 protein (Figure 2). Our structural prediction revealed that this mutation leads to partial loss of the kinase domain and complete loss of the C-terminal end of the $\alpha$-helix (Figure 3 ). This mutation has not yet been described in the literature.

All affected patients carried this novel mutation, but none of their unaffected relatives or normal controls had the mutation. Since the mutation clearly co-segregated with the disease phenotype in these two families, and the mutation was predicted to affect the expression of the STK11 gene product, we concluded that this mutation is disease-specific for these kindreds and not a polymorphic variant of the STK11 gene. Both families are from the southern part of China, and therefore it is probable that this mutation has a common origin, even though the two families were screened at different centers.

\section{Discussion}

The STK11 protein is mainly comprised of three major domains: an $\mathrm{N}$-terminal non-catalytic domain that contains the nuclear localization signal, a catalytic kinase domain that is important for ATP binding, and a C-terminal non-catalytic regulatory domain that contains a prenylation motif (CAAX-box) [10]. Codons 49-309 encode the catalytic kinase domain. The $\mathrm{C}$-terminal non-catalytic region of the STK11 protein is encoded by exon 8 and 9, and encompasses amino acids 309-433. In these two Chinese families, the mutation, c.904C > T (p.Q302X), results in the premature termination of the 433 amino acid protein at codon 302 , which leads to partial loss of the kinase domain and complete loss of the C-terminal regulatory domain (CRD). With this mutation, patient II:6 in family 1 developed colon adenocarcinoma at 60 years of age and died one year later, and patient II:2 in family 2 died from liver cancer at 45 years of age. These findings suggest that the novel mutation, p.Q302X, is 


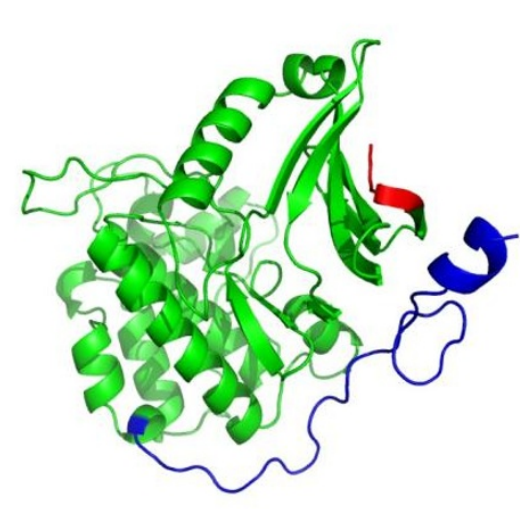

Wild-type

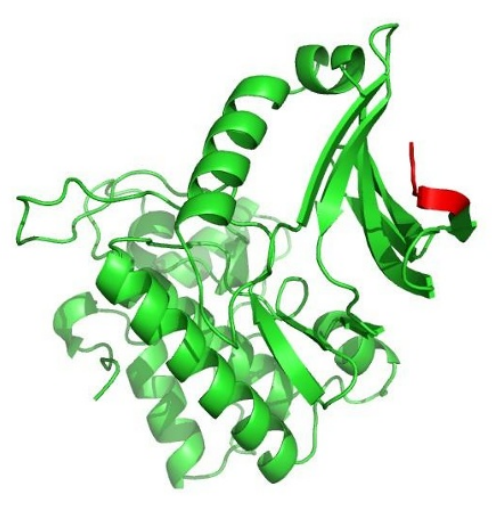

Mutant type (p.Q302X)

Figure 3 Structural modeling of the wild-type and mutant proteins. The STK11 protein is mainly comprised of three major domains: the $\mathrm{N}$-terminal non-catalytic domain in red, the catalytic kinase domain in green, and the C-terminal non-catalytic regulatory domain in blue. The mutation, p.Q302X, leads to partial loss of the kinase domain and complete loss of the C-terminal end of the $\alpha$-helix.

most likely responsible for the development of the PJS phenotype and may even contribute to malignancy.

Although the exact function of STK11 remains largely unknown, studies suggest that it plays a role in cell signaling and apoptosis [11]. Development of the PJS phenotypes is believed to be due to the elimination of the kinase activity of STK11, which is associated with a loss of growth suppression function [12]. Recently, several proteins, including p53, Cdc37, Hsp90, and PTEN, which are responsible for cancer syndromes when mutated or involved in cancer pathways, were reported to interact with the kinase domain of STK11; however, the protein interaction domains have not been mapped [13]. Accordingly, the interaction domain for one of these proteins may be localized to codon 302 , and therefore could explain the high cancer risk of mutations within this site. Moreover, the C-terminal domain of STK11 is important for binding STRAD, which is a protein that is possibly involved in MAPK signaling, control of the AMPK pathway (a key regulator of cellular metabolism), and control of cell polarity $[14,15]$. Taken together, these data suggest that the novel STK11 mutation, c.904C > T (p.Q302X), which was found in two unrelated Chinese PJS families, causes partial loss of the kinase domain and complete loss of the C-terminal domain, and may contribute to polyp formation and tumorgenesis through various mechanisms, such as loss of growth arrest, apoptosis, and loss of cell polarity. Additional studies are needed to address these questions.

A genotype-phenotype correlation has been sought in PJS. Schumacher et al. [16] suggested that in-frame mutations in the domains that encode the protein and ATP binding and catalysis (I-VIA) are rarely associated with cancer. Moreover, missense mutations in the
C-terminus and in the domains for substrate recognition (VIB-VIII) seem to be more associated with malignancies, and patients with breast carcinomas predominantly had truncating mutations. Mehenni et al. [13] suggested that there was a higher risk of cancer in cases with mutations in exon 6 of the STK11 gene. In a large analysis of 240 PJS patients with STK11 mutations, no difference was observed between individuals with missense and truncating mutations or between familial and sporadic cases, although it was suggested that there was a higher risk of cancer in individuals with mutations in exon 3 of the gene. Hearle et al. [2] extended this study by analyzing a total of 419 PJS patients, of whom 297 had documented mutations. In that study, it was found that the type and site of mutation did not influence cancer risk.

\section{Conclusion}

In our current study, we identified the novel mutation, p. Q302X, which was associated with cancers in both Chinese families where it was identified. Members of PJS families are at risk of developing the disease. Identification of a STK11 gene mutation in an index patient offers the possibility of a predictive diagnosis in PJS pedigrees. Furthermore, a possible genotype-phenotype correlation, especially concerning the risk of gastrointestinal and extraintestinal cancers, would be of particular clinical interest.

\section{Abbreviations}

PJS: Peutz-Jeghers syndrome; STK11: Serine threonine kinase 11; Gl: gastrointestinal; CRD: C-terminal regulatory domain; Cdc37: Cell division cycle 37; Hsp90: Heat shock protein; PTEN: phosphatase and tensin homolog deleted on chromosome ten; STRAD: STE20-related adaptor; MAPK: mitogenactivated protein kinase; AMPK: AMP-activated protein kinase. 


\section{Acknowledgements}

The participation of all PJS family members and patients and collaboration of the physicians and surgeons are gratefully acknowledged. Funding

Indentification of biomarker profile for early diagnosis in colorectal cancer and clinical pathology analysis. Science and Technology Development Program of Guangzhou MuniciPality 2060402. (2009)

\section{Authors' contributions}

ZQW carried out molecular genetic studies including sequencing for all the families and the controls, and drafted the manuscript. YLC did the structural predictions. BPW identified and diagnosed the patients. HXZ and JMH performed Gl examinations and provided histopathological information. BJ designed, supervised the study and revised the manuscript. All authors read and approved the final manuscript.

\section{Competing interests}

The authors declare that they have no competing interests.

Received: 1 November 2011 Accepted: 14 December 2011 Published: 14 December 2011

\section{References}

1. Giardiello FM, Brensinger JD, Tersmette AC, Goodman SN, Petersen GM, Booker SV, Cruz-Correa M, Offerhaus JA: Very high risk of cancer in familial Peutz-Jeghers syndrome. Gastroenterology 2000, 119:1447-1453.

2. Hearle N, Schumacher V, Menko FH, Olschwang S, Boardman LA, Gille JJ, Keller JJ, Westerman AM, Scott RJ, Lim W, Trimbath JD, Giardiello FM, Gruber SB, Offerhaus GJ, de Rooij FW, Wilson JH, Hansmann A, Moslein G, Royer-Pokora B, Vogel T, Phillips RK, Spigelman AD, Houlston RS: Frequency and Spectrum of Cancers in the Peutz-Jeghers Syndrome. Clin Cancer Res 2006, 12:3209-3215.

3. van Lier MG, Westerman AM, Wagner A, Looman CW, Wilson JH, de Rooij FW, Lemmens VE, Kuipers EJ, Mathus-Vliegen EM, van Leerdam ME: High cancer risk and increased mortality in patients with Peutz-Jeghers syndrome. Gut 2011, 60:141-147.

4. van Lier MG, Wagner A, Mathus-Vliegen EM, Kuipers EJ, Steyerberg EW, van Leerdam ME: High cancer risk in Peutz-Jeghers Syndrome: A systematic review and surveillance recommendations. Am J Gastroenterol 2010, 105:1258-1246.

5. Hemminki A, Markie D, Tomlinson I, Avizienyte E, Roth S, Loukola A, Bignell G, Warren W, Aminoff M, Hoglund P, Jarvinen H, Kristo P, Pelin K, Ridanpaa M, Salovaara R, Toro T, Bodmer W, Olschwang S, Olsen AS, Stratton MR, de la Chapelle A, Aaltonen LA: A serine/threonine kinase gene defective in Peutz-Jeghers syndrome. Nature 1998, 391:184-187.

6. Jenne DE, Reimann H, Nezu J, Friedl W, Loff S, Jeschke R, Muller O, Back W, Zimmer M: Peutz-Jeghers syndrome is caused by mutations in a novel serine threonine kinase. Nat Genet 1998, 18:38-43.

7. Aretz S, Stienen D, Uhlhaas S, Loff S, Back W, Pagenstecher C, McLeod DR, Graham GE, Mangold E, Santer R: High proportion of large genomic STK11 deletions in Peutz-Jeghers Syndrome. Human Mutation 2005, 26(6):513-519.

8. Wang ZJ, Churchman M, Avizienyte E, McKeown C, Davies S, Evans DG, Ferguson A, Ellis I, Xu WH, Yan ZY, Aaltonen LA, Tomlinson IP: Germline mutations of the LKB1(STK11) gene in Peutz-Jeghers patients. J Med Genet 1999, 36:365-368.

9. Giardiello FM, Welsh SB, Hamilton SR, Offerhaus GJ, Gittelsohn AM, Booker SV, Krush AJ, Yardley JH, Luk GD: Increased risk of cancer in the Peutz-Jeghers syndrome. N Engl J Med 1987, 316:1511-1514.

10. Hanks SK, Quinn AM, Hunter T: The protein kinase family: conserved features and deduced phylogeny of the catalytic domains. Science 1988, 1:42-52.

11. Shaw RJ, Kosmatka M, Bardeesy N, Hurley RL, Witters LA, DePinho RA, Cantley LC: The tumor suppressor LKB1 kinase directly activates AMPactivated kinase and regulates apoptosis in response to energy stress. Pro Natl Acad Sci USA 2004, 101:3329-3335.

12. Mehenni H, Gehrig C, Nezu J, Oku A, Shimane M, Rossier C, Guex N, Blouin JL, Scott HS, Antonarakis SE: Loss of LKB1 kinase activity in PeutzJeghers Syndrome, and evidence for allelic and locus heterogeneity. Am J Hum Genet 1998, 63:1641-1650.
13. Mehenni H, Resta N, Park JG, Miyaki M, Guanti G, Costanza MC: Cancer risks in LKB1 germline mutation carriers. Gut 2006, 55:984-990.

14. Baas AF, Kuipers J, van der Wel NN, Batlle E, Koerten HK, Peters PJ, Clevers HC: Complete polarization of single intestinal epithelial cells upon activation of LKB1 by STRAD. Cell 2004, 116:457-466.

15. Forcet C, Etienne-Mannevill S, Gaude H, Fournier L, Debilly S, Salmi M, Baas A, Olschwang S, Clevers H, Billaud M: Functional analysis of PeutzJeghers mutations reveals that the LKB1 C-terminal region exerts a crucial role in regulating both the AMPK pathway and the cell polarity. Hum Mol Genet 2005, 15:1283-1292.

16. Schumacher V, Vogel T, Leube B, Driemel C, Goecke T, Moslein G, RoyerPokoa B: STK11 genotyping and cancer risk in Peutz-Jeghers syndrome. J Med Genet 2005, 42:428-435.

\section{Pre-publication history}

The pre-publication history for this paper can be accessed here: http://www.biomedcentral.com/1471-2350/12/161/prepub

doi:10.1186/1471-2350-12-161

Cite this article as: Wang et al:: A novel mutation in STK11 gene is associated with Peutz-Jeghers Syndrome in Chinese patients. BMC Medical Genetics 2011 12:161.

\section{Submit your next manuscript to BioMed Central and take full advantage of:}

- Convenient online submission

- Thorough peer review

- No space constraints or color figure charges

- Immediate publication on acceptance

- Inclusion in PubMed, CAS, Scopus and Google Scholar

- Research which is freely available for redistribution

Submit your manuscript at www.biomedcentral.com/submit
C Biomed Central 